\title{
THE SPECIFICITY OF LANGUAGE IN PSYCHOANALYSIS
}

Cláudia Braga de Andrade

Cláudia Braga de

Andrade

Universidade

Federal de Ouro

Preto (UFOP),

Departamento de

Educação, Ouro

Preto/MG, Brasil.

\begin{abstract}
The following article aims to discuss the conceptions of language proposed in Freud's work, considering the specificity of the notion of representation, and to point out its consequences in clinical practice. In the representation theory, it is possible to conceive a notion of language characterized by heterogeneity (representation of the word and representation of the thing) that its effect of meaning is produced through a complex of associations and their linkage to an intensive approach (instinctual representative). From this model, it is assumed that the language exceeds its semantic function and the representational system is not restricted to the field of rationality and verbalization.
\end{abstract}

Keywords: Language, representation, psychoanalysis.

RESUMO: A especificidade dalinguagem na psicanálise. Oartigo tem por objetivo discutir a concepção de linguagem proposta na obra freudiana,considerandoaespecificidadedanoçãoderepresentação eapontar seus desdobramentosna prática clinica. Nateoria de representaçãoépossível conceberumanoçãodelinguagemcaracterizada pelaheterogeneidade (representação da palavraerepresentaçãoda coisa) em que seu efeito de significação é produzido através de um complexo de associações e sua vinculação a uma abordagem intensiva (representante pulsional). A partir deste modelo, admite-seque a linguagem excede a sua função semântica e o regime representacional não se restringe ao campo da racionalidadee da verbalização. Palavras-chave: Linguagem, representação, psicanálise.

DOI - http://dx.doi.org/10.1590/S1516-14982016002009 
$\mathrm{T}$ he psychoanalytic theory initiates a discursivity on clinical practice, introducing a new meaning for the function of language. The Freudian conception of language is marked by heterogeneity of two entries - representation of the word and representation of the thing - in which the effect of significance is produced through a complex of associations. With the notion of representative drive, Freud expands this discussion when approaching the question of intensity. The originality of this focus poses a questioning about the restriction of the system of representation to the field of rationality and verbalization, as well as of the exclusively semantic dimension of the language. It is a perspective that starts to consider the non-linguistic, alogical and ungrammatical aspect of the language?

We will highlight, then, how the specificity of the concept of representation built along Freud's work, especially in the study of the aphasias and the metapsychological texts, opens a new horizon on the approach of the language that implies different perspectives to the psychoanalytic clinic.

\section{AN INAUGURAL ENCOUNTER WITH LANGUAGE}

The inaugural encounter between Freud and the issue of language takes place in his study on speech pathology ${ }^{2}$. The research on the mechanism of aphasia takes Freud to a new approach about language. The central element which gives originality to the Freudian construction of the speech apparatus model is his

\footnotetext{
${ }^{1}$ In this article the German term vorstellung was translated as 'representation'. The term vorstellung has been translated as 'representation','presentation' or 'idea'. According to Hans, "the translation for'representation' has been more frequent, but due to the extensive polysemy of the Portuguese word 'represent', is easily mistaken by the terms darstellen, vertreten and repräsentieren, whose translation is also 'represent', but whose meanings in German are different from de vorstellen. The other translation alternatives ('idea', 'present', 'conceive' and 'imagine') also have specific meanings in Portuguese that not always are covered by vorstellen" " (Hans, 1996: 386). With respect to the terms wortvorstellung and sachevorstellung, following the same line, we have used the translations ' representation of the word' and 'representation of the thing' respectively-suggested by the translator Paulo César de Souza in "Complete Works volume 12" edited by Companhia das Letras (Freud, 2010/1915c:146). The terms in question have different translations in the Brazilian editions of the Freudian work. In the Standard Brazilian Edition of Freud's works, for example, a long footnote can be found indicating that the term vorstellung, in the article about the Unconscious was translated as presentation. In the note, Strachey asserts that the differentiation between wortvorstellung 'presentation of the word' and sachevorstellung 'presentation of the thing ' goes back to the studies on aphasia (Freud, 1976/1915:229).

2 Despite the text "Contribuition à la conception des aphasies" (Freud, 1987/1891) be considered a pre-psychoanalitical text, it is a landmark of Freud's inaugural encounter with the problem of language and it introduces a new formulation of representation, which will be resumed later along the theoretical construction of psychoanalysis.
} 
reformulation of the concept of representation, which marks a distance of the current conceptions of that time.

The Freudian theory of aphasias, elaborated under the order of the language, consists of a critique to the concept of anatomical theory, which tried to explain pathology through the terms of elementary locations, without distinguishing the conceptions of automatic language and spontaneous language. For Freud, it is not the repetitive dimension that defines the language in its entirety, the essentials of language is precisely its ability to develop new meanings and new semantic forms. The language is therefore designed under a holistic perspective, where the elements of the word are not designed in isolation. The formulation of the apparatus language as a whole and as a system suggests the idea that the psyche is basically represented in the form of the functioning of the language (Birman, 1993).

Freud proposes a hypothetical scheme - the unit of speech -to describe the neurological functioning of language in the learning process of speech, reading and writing. His interest is not on the language as a system, but in the processes involved in the activity of speaking and understanding. Language acquisition is designed as a learning that integrates sensory and motor in one indivisible unit. Learning is described in neurological steps of the formation of the language apparatus and the starting point is the representation of the word. All the construction and operation of the language apparatus are supported from the cleavage of the representations according to the order of the word and the order of the object.

The Freudian research on language disorders starts from the speech function unit-the word-a complex representation which combines several distinct sensory elements. Garcia-Roza (1991) notes that a 'complex representation' does not mean the effect of the 'unit' of the 'print' - as an elementarist design would be - but that its unit requires a number of elements that are located in different places of the territory of language. To say that the word is a complex representation means that any language operation implies a simultaneous intervention of functions relating to more than one point in the territory of language. Language consists of a process of association where the representations behave as the contents of the language apparatus.

The theoretical construction of the language apparatus is based on the opposition between the representation of the word and the representation of the object. The representation of the word is constituted by a series of four elementary records that indicate sensory channels of the body: the sound image, the visual image of the letter, the motor image of the speech and the motor image of the writing. The object representation is a complex of associations formed 
by a variety of representations that are linked to the sensory field: the visual representation, the tactile representation and the acoustic representation.

From the pathological analysis of speech disorders, Freud builds the hypothesis of the connection of the representation of the word through its sensory end (by sound images) to the representation of the object. The unit of the speech function is the 'word', a complex representation that is a combination of acoustic, visual and synesthetic elements. And the sound image of the word is the point of intersection of the two associative complexes. In 1891, this diagram is proposed with the following description:

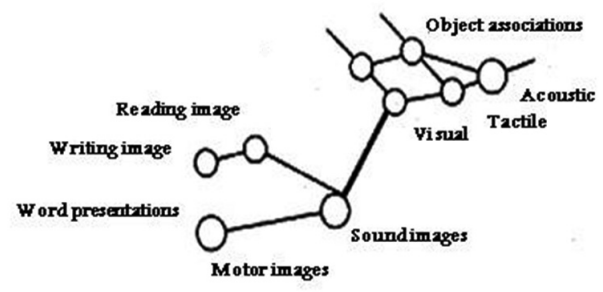

"The word representation is defined as a closed representational complex, while the objectrepresentation is defined as an open complex. The word representation is not related to the object representation by all its constituent parts, but only by the acoustic image. Among the various associations of the object, the visual ones are those that represent the object, in the same way that the acoustic image represents the word. "The connections of the acoustic image of the word with the other associations of the object, are not presented here" (Freud, 1987/1891:127).

The Freudian hypothesis is that the word representation complex refers necessarily to the representative of the object that, in turn, is constituted by a complex of associations formed by a wide variety of visual, acoustic, tactile, synestheticrepresentations, among others. The effect of signification is produced through the association of various elements of the object representation with the representation of the word. Therefore, a word only acquires a meaning when it is connected to a representative of the object. This way, when the connection of the word with the representation of the object is established, the language apparatus articulates representations that producea meaning. It is concluded that theFreudianunderstandingabouttheaphasicdiscourse providestheformulation of language as an effect of the operation of this apparatus. In this perspective, it is interesting to note that the language does not have only one encoding function, but an expressive and creative function.

Kristeva (2000) emphasizes that the Freudian model of speech apparatus considers the energy aspect, in that the kinds of figurability (or of representa- 
tion) are treated as language displacements. According to the author, this first Freudian model of language is characterized by heterogeneity, present in two the two representation records. In the word representations, the sound image depends on other sensory images of the word and, for this reason, cannot be assimilated to a significant pure; and in the representations of the thing something pictorial and strongly invested is evoked.

Based on a careful listening on aphasias, Freud builds a language apparatus model that will serve as a kind of embryo for the construction of the notion of psychic apparatus a few years later, especially in the discussion about the unconscious, when the role of language is explained in an even more evident way. From the criterion of language, the unconscious and pre-conscious processes are operated.

\section{THE ‘DYSFUNCTION' BETWEEN WORDS AND THINGS}

In his metapsychological texts, Freud resumes, under a new perspective, the cleavage hipothesis among representations exposed in the monography on aphasias. The psychic processes are exposed from the pair of the thing and the word representations, rather than theobjectand the word representations. At this point, Freud goes on to describe the object representation as a complex formed by the combination of the thing representation and the word representation (Freud, 2010/1915c). According to a certain point of view, the change from the object representation to the thing representation can denote more than a simple exchange of nomenclature, but a passage equivalent to a change in the theoretical field from the neurological period to the psychoanalytical period. The introduction of the concept of the thing representation in the metapsychological works corresponds to a new focus of the language. According to Assoun (1995), the term object indicates an objective direction, correlative to the idea and the word; while the term thing emphasizes the thinghood of the representational process itself, evoking the unconscious more directly. "Freud doesn't formulate the Unconscious brutal equation = Thing. (...) But he designates an irreducible point beyond verbalization, the real place of the unconscious - as the memory or storage of mnesic traits "(1995, Assoun: 85).

Laplanche and Pontalis (1986) point out that the idea of thing representation is present in Freud's work in the expression of mnesic traits represented by perceptual signs. In the item 'Unconscious identification' of the essay on "The unconscious" themost precise definition about the thing representation is found:

\footnotetext{
"Now what we might call conscious representation of the object breaks down to us in the word representation and the thing representation, which consists of an investment, if
} 
not direct, of mnemonic images of the thing, at least of the more distant memory and those derived from them" (Freud, 2010/1915c: 146).

In the metapsychological texts, the thing representation finds a match with the mnemonic traits. Derived from the satisfaction experience, the traits may or may not be translated into verbal signs, through the connection with the word representation. The expression of the unconscious representation includes, therefore, that thing from the object which is part of the mnesic systems.

The definition of the representations in the order of the word and the order of the thing becomes associated with the psyche structure as an operator of the theory of the unconscious. This difference has a fundamental topic value, because the link between the thing representation and the word representation corresponds to the unconscious system and to the preconscious and conscious system. These psychic systems correspond to two operating modes of psychic processes and two articulation modes between the representations. While in the unconscious system there is extreme mobility of the intensities of investment characteristic of the primary psychic process; the preconscious/conscious system is regulated in accordance with the secondary procedure which is characterized by a more stable investment of representations (Freud, 2010/1915c).

Freud focus in the role of language in the delimitation between the unconscious processes and the conscious processes and formulates someassumptions: the pre-conscious system is characterized by its verbal representations; the psychological process of making conscious is linked to the verbal expression of the thing representation; the word representations are introduced in a concept that links verbalization and the taking of consciousness. However, the fact of the pre-conscious system be coupled to the word representations, this still doesn't make it conscious (Freud, 2010/1915c). These Freudian assumptions lead to question about the relationship between the secondary process and the verbal thought. This is a topic marked by paradoxes in the Freudian text, because the predominantrelationshipinmetapsychologybetweenthesecondaryprocessand the verbal thinking is quite complex. Let's see how Freud develops this question from the parallel between the unconscious logic present in psychosis (and in dreams) and the logic of neurosis, in the mechanism of repression.

With the purpose of advancing his formulation on the unconscious processes, Freud turns to the representational dynamics of psychosis logic and the dream logic. What approaches the two cases is that the words can be treated like things. Both in the oneiric processes as in psychosis there is a withdrawal of the libido of the objects and of the reality that creates conditions for the regression to the primary process and makes it possible the manifestation of the 
loss of more complex ${ }^{3}$ linguistic relations. In the case of the dream theory the verbal ambiguities are unveiled, for in the dream all operations with words are no more than a preparation for a regression of things. The synthesis of Freud is that the elaboration of the dream little complies with the word representations; the oneiric work, all the time, "is willing to swap the words for each other, to find the most compelling expression to the plastic representation" (Freud, 2010/1915d: 160). In schizophrenia the words are also subject to the primary process and to the actions of displacement and condensation such as the images in dreams. The replacement is not defined by the similarity in the denoted things, but by the uniformity of words employed to express them (Freud, 2010/1915c).

In the representational scheme of psychosis there is a mismatch between the word and the thing causing a literal relationship with the word. Due to a superinvestiment of verbal representation, the word is treated as if it were a thing. As Forrester (1980) indicates, different from the neuroses, in psychosis there is no shortage of words, just the opposite, this offers a plethora of words, of a language system that is separate from all connection with the unconscious thoughts controlled by the activity of the 'self'.

Whereas in psychoses the relationship between the representations of the word and the thing is interrupted, in neuroses this path is still likely to be followed, as is the case in the process of neurotic repression. The difference is to define which aspect of the thought is hidden, if the thing representation or the word representation. Freud (2010/1915c) is very clear in his statement that a representation that is not put into words, or a psychic act that is not hypercathected, remains in the unconscious in a state of repression. Therefore, the repression mechanism is not restricted to preventing that an unconscious representation becomes conscious, but to preventing that the representation of the thing be translated into words. In this perspective, repression is the disconnection between the word representations and the thing representations. The clinic of neurosis demonstrates exactly this breach between the word and the thing. Given this panorama, it would be deductible that, in this model presented by Freud, the destination of the thing representation would be its verbalization and its awareness. However, the Freudian model presents another complexity in therelationshipbetweenthesecondaryprocessand theverbalthought. Although language is a condition for the connection of the secondary process operation, the presence of verbal representations does not guarantee the operation in sec-

\footnotetext{
${ }^{3}$ In the 'Outline of Psychoanalysis', Freud makes a clear reference to the dream as a 'short lasting' psychosis. "A dream, then, is a psychosis, with all the absurdities, delirium and delusions of a psychosis. A short-lasting psychosis, without a doubt, harmless, even with a useful function, introduced with the consent of the individual and completed by an act of will." (Freud, 1976/1938:199).
} 
ondary process of the pre-conscious system. The processes of thought, devoid of quality and unconscious, only reach their capacity to become aware through the connection with the remains of words. And, both word representations as things representations originate from sensory perceptions (Freud, 2010/1915).

The link between quality and verbal residues is recurrent in the Freudian work. In "Interpretation of dreams (1900), Freud already insisted on the idea that the thought processes acquire qualities when associated to verbal memories, whose quality residues are enough to attract the attention of consciousness. In "Formulations on the two principles of mental functioning" (1911), Freud presents again the hypothesis that thinking goes beyond a simple ideational representation. Influenced by the relationship between prints and objects, the thought acquires other noticeable qualities to consciousness when it connects to the verbal residues.

In the restructuring of the psychic apparatus, in 1923, Freud understands the role of the word representation as a mediation of the conscious processes of thought.Throughtheoppositionwordrepresentationandthingrepresentationhe replaces thequestion about the distinction between conscious and unconscious. In relation to language, he keeps the proposition that the unconscious representations are distinct from the verbal ones. Through language, the representations when associated with verbal representatives reach consciousness. From this perspective, there is no language in the unconscious; the language would be on the grounds of the pre-conscious. It is precisely located in an intermediate position between the unconscious and the conscious (Kristeva, 2000). Freud is accurate in his statement:

"The real difference between an unconscious or preconscious representation is that the former is performed in some material that remains unknown, while the latter is placed in connection with verbal representations. This is the first attempt to indicate distinguishing marks between both systems, the Pcs and the Ics, in addition to its relationship with consciousness "(Freud, 1976/1923:33).

Assoun draws attention for the fact that in the essay 'The Ego and the Id', the opposition focuses directly on the unconscious representation as pure and simple vorstellung that matches something not recognized, a kind of disqualified and anonymous matter. "The being of the word representation is relational, to the extent that it arises from a connection or a link with the other, the raw representation. An idea to be brought into line with the relational nature of the linguistic sign and, beyond it, with the relational being of the significant itself" (Assoun, 1995:89). 
Atfirst, thefact that the unconscious doesnot'communicate'-unlessthrough the connection with the verbal representatives-can give a predominance to the relationship between verbal thought and its awareness. However, it is also present in this hypothesis the idea that it's not exactly the thing representation, this anonymous and unseen material that awareness is made possible. Awareness is achieved through the articulation between the words and the traits that are irreducibly unconscious.

Anotherimportantpointtohighlightintheoriginal languagedesign proposed by Freud, concerns the binding between representability and the sense organs. The exposition of the theme in aphasias and in the essay on the unconscious already mentions the prevalence of the auditory aspect in the word representation. In 1923, Freud defines that the verbal residues mainly derive from the auditory perceptions so that the Pcs system has a special sensory source. In essence, "a word is, ultimately, the mnemonic residue of the word that was heard" (Freud, 1976/1923:34). This statement sets out two formulations. Firstly, only the preconscious system can be presented in the form of verbal. Secondly, for a representation to becomeconscious the preconscious representationswillsearch for the mnesic remains of the words that were once heard. Kristeva highlights the drive relationship in the formulation of the verbal residues "It is because there have been perceptions in the words that these words-perceptions can be connected to the drive at the same time and thus to the body investment. Words at the crossroads between the mnemonics and the conscience" (Kristeva, 2000:87).

The emphasis on the acoustic dimension of the word representation had already been mentioned in the study of aphasias. The Freudian model conceives that the word representation is essentially acoustic while the object representation is visual. Understanding the word primarily as a mnemonic residue of a perception indicates, above all, its recovery as a form of expression more than its own meaning. The situation in which the sounding of the word is a priority over the meaning of the word, shows a perspective that is also present in the investigations about the wits. In the research on the relationship of the wits with the unconscious, Freud clearly demonstrates his interest in the dimension of expression. "In a certain group of these wits (word play), the technique was to focus on our psychic attitude in relation to the sound of the word instead of its meaning - to make that the presentation (acoustics) of the word takes the place of its meaning, as determined by its relations with the thing representations" (Freud, 1976/1905b: 141). 


\title{
DRIVE AND LANGUAGE
}

The relationship between word and thing representations is reviewed when the psychic apparatus begins to be analyzed from the perspective of the drive. The drive becomes the condition of representations. The representatives that are at stake are not of the word neither of the thing, but of the drive, and the drive itself is never represented. According to Freud (2010/1915c), a drive can never be the object of the conscious or the unconscious. And even in the unconscious it cannot be represented in any other way except by a representation. ${ }^{4}$

\begin{abstract}
"a drive can't ever become an object of consciousness, just the idea that it represents. But also in the unconscious it cannot be represented except for the idea. If the drive did not hold to an idea or did not appear as an affective state, we couldn't know anything about it. But if, however, we speak of an unconscious impulse or a repressed impulse, it is harmless speech neglect. We can only be referring to an impulse whose ideational representative is unconscious, because something else could not be taken into consideration "(Freud, 2010/1915c: 114-5).
\end{abstract}

Freud defines the representative-representation as a representation or a set of representations instinctually invested. Therefore, the drive cannot become directly an object of consciousness, only through its mediators. The Freudian claim that a drive is only present in the psyche through its representatives emphasizes the distinction between two elements: arepresentation of theideational character and a way of drive presentification with a purely intensive character. Therefore, the instinctual drive in its psychic expression is unfolded in idea and affection. It is through the repression mechanism that Freud clearly explains the opposition between the two psychic representatives of the drive: the ideational representative and the affection. This opposition is organized, in a clear distinction to psychoanalysis, since it is from here that Freud maintains a 'cornerstone' to the understanding of the neuroses.

In the essay on repression, as well as highlighting the distinction between the two components of the drive, Freud reflects on the representative position of the representation in relation to affection. The repression focuses solely on representations - thoughts and images - linked to a drive. The implication between the two drive elements is described as follows:

"In our discussion, up to this moment, we have been dealing with the repression of an instinctual representative, that is, an idea or a set of ideas invested of a certain amount of psychic energy (libido, interest) from the drive. The clinical observation

\footnotetext{
${ }^{4}$ We have chosen to standardize the references to the concept of trieb as 'drive'.
} 
takes us now to decompose what until then we have grasped as a unit, because it shows us that it's necessary to consider, in addition to the idea, another thing that represents the drive, and the fact that it experiences a target of repression that can be entirely different from the idea. (...)

From now on, when describing a case of repression, we must follow separately what resulted from the idea, due to repression, and what happened to the instinctual energy to what it was connected "(Freud, 2010/1915b: 91-2, emphasis added).

The repression of representation does not synthesize theentire functioning of the repression.Changes in theamount of energy investment havea predominant role both on the repressed contents, as in the maintenance of repression. What is prevented from becoming conscious is not exactly the psychic representative (representative-representation) of the drive, but the psychic representation with a certain amount of psychic energy. In reference to the existence of two instinctual representatives there is a special appreciation of the role of affection in the functioning of repression. It is from the quantitative factor that the vicissitude of representation is defined. Freud (1976/1915b) considers that the quantitative factor will be decisive, because the activation of repression depends on the idea exceeding a certain degree of intensity. But the success in the performing of the repression functioning is also related to the destination of the share of affection.

\footnotetext{
"We recall that the reason and the purpose of suppression were meant just to avoid displeasure. It's known that the destination of the affective amount of the representative is far more important than that of the idea, and this is decisive for the judgment of the suppression process. If suppression fails to prevent the emergence of displeasure feelings or anxiety, then we can say that it has failed, even if it has achieved its goal in the ideational aspect "(Freud, 2010/1915b: 93, emphasis added).
}

With the expression quantum of affection - a quantitative factor postulated as a substrate of affection subjectively lived-Freud points out his economic hypothesis. The importance of the economy of the psychic apparatus in the defense mechanisms of neuroses had already been the subject of psychoanalytic research. In 1894, in the article on "The Neuro-psychoses of Defense", Freud starts from the assumption that the quantum of affection (or sum of excitement) is distinguished from mental functions. Although it can't be measured, it presents all the characteristics of quantity (growth, decrease, displacement and discharge). It is comparable to the electric charge that expands on the surface of the body, in the same way as it spreads on the memory traces of the ideas.

But how is this economic approach of affection related to representation? A distinction that was valued in the Freudian text is the difference between investment and intensity. In the article on the unconscious, trying to consider the 
linguistic use of unconscious affections, Freud states that: the difference comes from the fact that "ideas are investments - in fact, of mnemonic traits -, while affections and feelings correspond to discharge processes, whose final expressions are perceived as sensations (Freud, 20101/915c: 117). From the economic point of view, representation is assimilated to the investment order with traces of memory, while affection to the order of intensity of discharge. Garcia-Roza (1995) understands that the investment corresponds to the intensive dimension of representatives-representation, being therefore, part of the affection that originally was connected to representation. In this sense, the investment is not a determined quantum of affection which occupies a representation, but something that links the scattered traces, forming the representatives-representation arrangement.

The fact is that the clarification that Freud tries to offer to demonstrate the notion of instinctual psychic representative through theoperation of repression is full of ambiguity. Associating representative to investments and affection to discharge, far from solving the problem, makes it even more obscure. And, this issue supports a far-reaching metapsychological debate in the field of psychoanalysis.

From the metapsychological essays, the linking of representation to the notion of instinctual representative is highlighted. The notion of representative is necessary for its own condition of drive-a limit concept between the psychic and the somatic. In this complex matter about representation and its articulation with the instinctual circuit, it is possible to demarcate a difference between a reading that conceives the drive itself as representative and another that considers the drive as psychically represented by its representatives (Garcia-Roza, 1995). This condition allows some ambiguity in the use of the term, sometimes the drive is assimilated to the psychic representative of somatic strength and sometimes it is leveled to the process of somatic excitement that is represented in the psyche by the representatives of the drive.

In the book Three essays on the theory of sexuality, when the concept of drive is assimilated to the sexual drive, Freud is concerned in determining its nature. The drive is defined as a psychic representative of a continuous force of excitement coming from within the body. In the same text, in an addition dating from 1915, the drive is defined as: "a psychic representative of an endosomatic and continuous source of excitement in contrast to a 'stimulus' that is established by simple excitement coming from outside" (Freud, 1976/1905a: 171). Freud makes equivalence between drive and its psychic representative, leaving doubts if the drive belongs essentially to the psychic plane. The representative function of the drive is due to an accumulation of somatic energy transformed into psychic energy. The theory of neuroses, created at the same time, exposes the energy 
transformation or communication between two levels - the undifferentiated energy can be represented in the psychic form. At this moment, there is an emphasis on the qualitative reading of the drive and the quantitative aspect, its strength, is thought in the field of psychic representations.

We will find in the works of 1905 (Three essays) and 1915 (metapsychological articles) many references that seem to reserve the term of drives for the psychic manifestations; however it is possible to observe that in this passage the issue of drives is slightly changed. The drive then starts to designate not only the drive force and power that would be translated in the psyche, but also the form of psychic manifestation of this force (Tort, 1966). The problem so far was: how the endogenous excitement (somatic) or drive was translated in the psyche (as psychic excitement). In this movement, there would be no need to think about the psychic translation of the drive, once it becomes the psychic representative. At first there would be no contradiction in this assertion, since to determine the nature of the drive, Freud finds two possible approaches: the biological side of the excitement and psychological strength to the forms of truly psychic manifestations.

In 1915, in the article about drives, Freud highlights the originality of the fundamental concept of psychoanalysis: its quality of frontier concept. The essential nature of the drives is the constant force that originates within the body, defined as 'a stimulus applied to the mind that originates in the body itself.' The motor factor of the continuous pressure of the stimuli addresses to the psychic a work requirement-to master the stimuli. The drive then mediates between the somatic - source of stimulation — and the psychic — place of representations. It is only through its representatives that it is present in the psyche. The drive is defined primarily as a psychic representative of excitement (Freud 2010/1915a). Tort (1966) believes that in this duality the mystery of the transformation of energy or psychic development remains. So, referring to the term 'psychic representative' is the same as giving a different name to the same problem. Despite the complex and problematic Freudian mounting of drives, it is however important to emphasize the originality in placing the concept in an "in-between" position, 'between' force-representation.

Another complexity in the formulation of the concept of drive is the combination of its psychic representatives. The drive features a double record, the instinctual psychic representative unfolds in representation and affection. Therefore, the drive is represented in psyche by two representatives, the ideational representation and the affection. As representation, in its own condition, is one of the forms of instinctual 'representance', the term 'representative-representation' was forged (1995, Assoun: 84). 
There is a clear tendency to perform a reading 'sharing' the drive representative in two: the term representation for the qualitative/ideational content and the term affection for the quantitative/energetic component. It demonstrates, on the one hand, an attempt to put the affection on the side of the representation in order to recognize its legitimacy, as a representational symmetric. On the other hand, an initiative to recognize the representative-representation as the definite representative and affection as a kind of 'margin' (Assoun, 1995) is made evident. Although this division supports different theoretical and clinical positions, both in a field as in the other, the inadequacy of separation between the representative element and the energy affective element is defended. One of the misconceptions of this dichotomized reading of the drive would be to consider it as an external apparatus unlinked from the unconscious that would be represented by the idea or by the affection.

The discussion on the distinction of the representatives is elicited when one tries to recognize the status of legitimacy to one of them. When one chooses to use the term quantum of affection and not affective representative, some questions are raised: to what extent does Freud recognize symmetry between affection and representation? If in one hand, affection and representation appear as equal representatives of the drive, on the other, it is clear that they occupy differentiated positions.

The Freudian text allows you to interpret affection as a component part of the psychic representative, as an intensive element and the ideational representative as the significant element. In this respect, affection would be the drive manifestation; this means that the quantum of excitement is expressed psychically in the form of a quantum of affection that remains outside the significant framework. Considering affection as discharge is a way to bring it closer to the somatic source of the drive. Affection expresses in the most direct way the drive's commitment with the body, while the ideational representations would constitute the significant network characteristic of the unconscious. Affection appears as something of the order of the 'event' and you can't talk about it except through its quantitative element - its discharge. This perspective can lead us to associate affection to 'raw' drive, this one defined as discharge. Following this reasoning, affection would be compared to a sort of "drive subjectivation from which the 'representation' was removed, i.e., the drive that was not captured and submitted to representation (.1995 Assoun: 153).

\section{FINAL CONSIDERATIONS}

In the analysis of the metapsychological essays, we can highlight how the construction of the concept of instinctual representative brings a new horizon for the 
discussion about the specificity of the concept of representation and its binding to the notion of intensity. A foreground lies in the formulation of the drives, proposed in 1905, which values, especially, its qualitative aspect. The drive is entered in the register of representations, where an ordered instinctual circuit is constituted. This approach supports the formulation of a clinic devoted primarily to the production of meaning. Thus, the analytical work would be to promote the field of representations and make them aware, through the technique of interpretation. The key point of this argument is supported in the understanding that the process of becoming aware is associated to verbalization. The language is conceived as a representative and verbal activity, deeply committed, in turn, to the metaphysical logic of representations. The plan of intensities, although respected, is not determinative in the 'main' process of producing meaning from the flow of representations. In this case, the language is defined as the 'way' through which one produces the meaning of affection. In this perspective of associating the process of being aware to verbalization, body and affection become, practically, passive elements in the process.

In psychoanalysis we can find the coexistence of conceptual lines that focus on the field of representation alongsideothers that focus on the field of instinctual intensity which implies in different destinations of subjectivation (Schneider, 1994). We believe that the issues on the notion of language is the main question at stake when we deal with the controversies in the fundamentals of an analysis based on the discourse and acting by the effects of the representatives, and of an analysis on the instinctual dynamic. We believe that the fundamental axis in the support of analytic practice lies in the difference between a language capable of arousing affections and an affected language by itself.

Recebido/Received: 30/10/2014. Aprovado/Accepted: 23/4/2015.

\section{REFERENCES}

ARAÚJO, Saulo F. (2003) "O conceito freudiano de representação no texto Zur Auffassung der Aphasien", in: Revista Olhar (CECH/UFSCar), Ano 5, n. 8, Jan-Jun.

ASSOUN, Paul-Laurent (1995) Metapsicologia freudiana. Rio de Janeiro: Jorge Zahar Editora.

BIRMAN, Joel (1993) "A linguagem na constituição da psicanálise", in: Ensaios de teoria psicanalítica. Parte I. Rio de Janeiro: Jorge Zahar Editora. . (1996) Por uma estilística da existência. São Paulo: Ed. 34. 
FORRESTER, John. (1980) Le langage aux origines de la psychanalyse. Paris: Ed. Gallimard.

FREUD, Sigmund (1987/1891) Contribution à la conception des aphasies. Paris:PUF.

. (1976) Edição Standard Brasileira das obras psicológicas completas de Sigmund Freud. Rio de Janeiro: Imago Editora.

(1894) "As neuropsicoses de defesa", vol. III.

(1900) "Interpretação de sonhos", vol. IV,V.

(1905a) "Três ensaios sobre a teoria da sexualidade", vol. VII.

(1905b) "Os chistes e sua relação com o inconsciente", vol. VIII.

(1911) "Formulações sobre os dois princípios do funcionamento mental", vol. XII.

(1915) "O inconsciente", vol. XIV.

(1923) "O Ego e o Id", vol. XIX.

(1938) "Esboço de psicanálise", vol. XXIII.

. (2010/1915) Introdução ao narcisismo: ensaios de metapsicologia e outros textos (1914-1916) / Sigmund Freud; tradução e notas Paulo Cesar de Souza. São Paulo: Companhia das Letras.

(1915a) "Os instintos e seus destinos"

(1915b) "A suppression"

(1915c) "O inconsciente"

(1915d) "Complemento metapsicológico à teoria dos sonhos"

GARCIA-ROZA, L.A. (1991) Introdução à metapsicologia freudiana. vol.1. Rio de Janeiro: Jorge Zahar Editora.

(1995) Introdução à metapsicologia freudiana. vol. 3. Rio de Janeiro: Jorge Zahar Editora.

HANS, Luiz. (1996) Dicionário comentado do alemão de Freud. Rio de Janeiro: Imago Editora.

KRISTEVA, Julia (2000) Sentido e contra-senso da revolta. Rio de Janeiro: Ed. RocCO.

LAPLANCHE J. \& PONTALIS J.B. (1986) Dicionário de psicanálise. São Paulo: Ed. Martins Fontes.

SCHNEIDER, Monique (1994) Afeto e linguagem nos primeiros escritos de Freud. Sao Paulo: Escuta.

. (1999) "L'emotion selon Freud. L'interruption du corps etranger", in: Revue Phenomenologique, no. 7 p. 213-232.

TORT, Michel (1966) "A propos du concept freudien de representant", in: Cahier pour l'analyse. Paris.

Cláudia Braga de Andrade

cb.andrade@terra.com.br

Traduzido do português por Doris Dana/translated from portuguese by Doris Dana

dorisdana@uol.com.br 